\title{
Minireview
}

\section{Circulating endothelial cells in oncology: pitfalls and promises}

\author{
MH Strijbos', JW Gratama', J Kraan', CH Lamers', MA den Bakker² and S Sleijfer,, \\ 'Department of Medical Oncology, Erasmus University Medical Center, Rotterdam, The Netherlands; ${ }^{2}$ Department of Pathology, Erasmus University \\ Medical Center, Rotterdam, The Netherlands
}

\begin{abstract}
Adequate blood supply is a prerequisite in the pathogenesis of solid malignancies. As a result, depriving a tumour from its oxygen and nutrients, either by preventing the formation of new vessels, or by disrupting vessels already present in the tumour, appears to be an effective treatment modality in oncology. Given the mechanism by which these agents exert their anti-tumour activity together with the crucial role of tumour vasculature in the pathogenesis of tumours, there is a great need for markers properly reflecting its impact. Circulating endothelial cells (CEC), which are thought to derive from damaged vasculature, may be such a marker. Appropriate enumeration of these cells appears to be a technical challenge. Nevertheless, first studies using validated CEC assays have shown that CEC numbers in patients with advanced malignancies are elevated compared to healthy controls making CEC a potential tool for among other establishing prognosis and therapy-induced effects. In this review, we will address the possible clinical applications of CEC detection in oncology, as well as the pitfalls encountered in this process.
\end{abstract}

British Journal of Cancer (2008) 98, I73I-1735. doi:I0.1038/sj.bjc.6604383 www.bjcancer.com

Published online 27 May 2008

(C) 2008 Cancer Research UK

Keywords: CEC; endothelium; angiogenesis; vasculature; biomarker; endothelial cells

Angiogenesis is thought to be an absolute prerequisite for the growth and dissemination of malignant tumours. When a tumour reaches a size of $1-2 \mathrm{~mm}^{3}$, its microenvironment can no longer provide the required amount of nutrients and oxygen by diffusion. The resulting cellular hypoxia initiates a response in malignant cells: the so-called 'angiogenic switch' (Naumov et al, 2006). By upregulating the expression of proangiogenic proteins, the tumour induces sprouting of pre-existing capillaries, which result in the formation of new vessels.

The pivotal role of angiogenesis in tumour growth prompted the development of several agents targeting receptors or signal transduction pathways involved in angiogenesis. Based on data from randomised clinical trials, the benefit of compounds that inhibit angiogenesis has already been demonstrated in several types of cancer, including metastatic colon carcinoma (Kabbinavar et al, 2003), renal cell carcinoma (Motzer et al, 2007), and nonsmall lung cell carcinoma (Sandler et al, 2006). In addition to these drugs inhibiting angiogenesis, another class of anticancer drugs, vascular disrupting agents (VDAs), has recently been developed and is designed to target already established tumour vasculature. Clinical studies exploring the latter drugs are currently ongoing.

Given the important role of angiogenesis in oncology in terms of pathogenesis as well as being a target for treatment, there is an increasing need for markers that accurately reflect effects impacting tumour vasculature. A promising candidate to serve as such a marker is the enumeration of circulating endothelial cells (CEC). CEC are mature endothelial cells, sloughed off the vessel wall as a result of vascular insults. Their number in peripheral blood is considered to reflect the extent of vascular damage in patients with vasculopathies. Recently, several assays for their

*Correspondence: Dr S Sleijfer; E-mail: s.sleijfer@erasmusmc.nl Received 10 December 2007; revised 2 April 2008; accepted 8 April 2008; published online 27 May 2008 detection and quantification have been developed. Although consensus on the phenotypic definition of CEC as well as on the optimal enumeration technique is still lacking, the number of clinical studies assessing CEC in cancer patients is rapidly expanding. Several studies on CEC also incorporate a strategy to enumerate endothelial progenitor cells (EPC), which, in contrast to $\mathrm{CEC}$, are thought to originate from the bone marrow and to contribute actively to angiogenesis. A study by Lyden showed in a murine model that, all tumour vessel endothelial cells were bone marrow-derived (Lyden et al, 2001), and similar observations were done in humans (Peters et al, 2005), stressing the importance of EPC in angiogenesis. However, as the frequency of EPC in blood is suggested to be several times lower than those of CEC, while additionally, their exact phenotype has not been elucidated, it is very difficult to reliably detect and enumerate EPC by currently available assays. EPC are therefore not included in this article.

This review provides an overview of the uses of CEC as surrogate marker for vascular damage in oncology, in particular technical issues concerning their detection, its potential applications, and results from clinical studies obtained so far.

\section{TECHNICAL ISSUES IN CEC ENUMERATION}

Currently, there are several assays described for the detection and enumeration of CEC. All these assays have to deal with the low number of CEC in peripheral blood, (typically 0-20 CEC per $\mathrm{ml}$ in healthy donors) rendering such assays highly susceptible to errors in sampling, preparation, and analysis. For instance, several groups have demonstrated the negative impact of venipuncture, as traumatically detached CEC contribute significantly to CEC counts (Goon et al, 2006; Rowand et al, 2007). Because of this low number, enrichment steps are applied in several approaches, 
which inevitably leads to cell loss and underestimation of the actual CEC number. Next to proper sampling, thorough analysis of enrichment efficacy, reported in terms of purity and recovery is therefore mandatory before using such assays based on enrichment in the clinic. The EUROCEC network has provided useful suggestions on how such a validation might be performed in practise (www.eurocec.com)(Woywodt et al, 2006).

Of key importance for proper detection and enumeration of CEC is the use of specific markers. However, the endothelium is a highly dynamic structure, closely involved in haemostasis, inflammation, regulation of vascular tonus, and angiogenesis. This dynamic process is accompanied by changing immunophenotype of endothelial cells that may largely account for the large number of different CEC phenotypes reported in literature. For enumeration of the total CEC number, and not a particular subpopulation, it is necessary to identify markers that are specific for and are constantly expressed by all CEC. Currently, no marker is considered to meet these criteria. Consequently, assays rely on multiple characteristics to define CEC. The majority of current assays define CEC as being positive for the CD146 antigen, present on endothelial cells, but also on a subset of activated T-cells, and melanomas (Elshal et al, 2005). Table 1 provides an overview of markers frequently used in CEC assays. As the different reported phenotypes render it impossible to compare results between various studies, consensus on a common endothelial cell phenotype is a key issue.

Another mandatory step in the development of CEC assays is the validation of the true endothelial origin of cells designated CEC by that assay. For this purpose, several unique features of endothelial cells can be used. These include uptake of Ulex Europaeus Lectin-1, or UEA-1 (Goon et al, 2006) or the ability of CEC to scavenge acetylated low-density lipoproteins, which can be visualised when labelled with $1,1^{\prime}$-dioctadecyl-3,3,3', $3^{\prime}$-tetramethyl-indocarbocyanine perchlorate (Dil Ac-LDL) (Voyta et al, 1984). In addition, immunohistochemistry or immunofluorescence can be used to demonstrate the presence of von Willebrand factor (VWF), or other endothelial surface markers (Table 1).

Another means of validation is through gene expression profiling assessing whether or not expression of endothelial genes such as vascular endothelial cadherin (VE-cadherin), is present in the population of cells designated as CEC (Smirnov et al, 2006).

\section{AVAILABLE ASSAYS}

\section{Manual immunomagnetic isolation}

The most widely used method to isolate CEC, is by the use of magnetic beads coupled to a monoclonal antibody ( $\mathrm{mAb}$ ) targeting CD146, as first described by Dignat-George (George et al, 1992). After isolation, additional techniques, such as flow cytometry or microscopic analysis, are used to identify CEC based on morphological or immunophenotypical criteria. A major advantage of this technique is that it permits visual identification of CEC, which allows them to be discriminated from endothelial micro particles, anuclear cells, and cellular conglomerates. However, manual beadbased isolation has several shortcomings, especially with regard to large monitoring studies. It is labour-intensive, requires a high level of operator skills, and requires additional steps to positively identify CEC, which make them unsuitable for high throughput monitoring. Furthermore, magnetic enrichment may give rise to an underestimation of the actual number of CEC. As CD146 expression on CEC is lower than on the HUVEC used to test assay recovery, its expression by CEC might be insufficient to bind to magnetic beads.

\section{Automated isolation and staining}

A variant on techniques applying a manual immunomagnetic enrichment step, is the CellTracks AutoPrep and CellTracks Analyzer II System (Immunicon Corp, Huntington Valley, PA, USA), initially designed to detect circulating tumour cells. As with manual immunomagnetic isolation, cells are isolated by CD146coupled ferrofluids, with the main difference being that the CellTracks System is fully automated, and is therefore not operator dependent. After isolation, the suspension of $\mathrm{CD}_{146^{+}}$cells is stained with (i) 4',6-diamidino-2-phenylindole (DAPI) to identify nucleated cells, (ii) CD105, fairly unique on endothelial cells, and (iii) CD45, to exclude CD146-expressing T cells. The enriched and stained sample is dispensed in a magnetic cartridge to form a monolayer of cells, which is scanned by the CellTracks Analyzer II System. The generated images are evaluated for CEC by visual inspection, in which CEC are defined as $\mathrm{DAPI}^{+}, \mathrm{CD}_{105^{+}}$, $\mathrm{CD} 146^{+}, \mathrm{CD}^{-} 5^{-}$(Rowand et al, 2007). The endothelial feature of the cells meeting these phenotypic criteria was further demon-

Table I Markers used in CEC assays

\begin{tabular}{|c|c|c|c|c|c|}
\hline Marker & Description & Subtype association & Expression level & Coexpression & References \\
\hline CD31 & PECAM-I & Pan-endothelial & $++^{\mathrm{a}}$ & P, Pan-leukocyte & (Beerepoot et al, 2004) \\
\hline CD34 & Stem cell marker & Pan-endothelial & $++^{\mathrm{a}}$ & $\mathrm{S}$ & (Furstenberger et al, 2006) \\
\hline CD36 & Collagen receptor I & Micro vascular & $+^{\mathrm{a}}$ & $P, E, M, D$ & (Moroni et al, 2005) \\
\hline CD54 & ICAM-I & Inflammation & $+{ }^{\mathrm{a}}$ & $L, M$ & (Dixon et al, 2004) \\
\hline CD62-E & E-selectin & Inflammation & ++ & - & (Dixon et al, 2004) \\
\hline CD62-P & P-selectin & Inflammation & + & $P$ & (Corcoran et al, 2006) \\
\hline CDI05 & Endoglin & Angiogenesis, malignant & $++^{\mathrm{a}}$ & $S, M^{b}$ & (Rowand et al, 2007) \\
\hline CDI06 & VCAM-I & Inflammation, malignant & $+^{\mathrm{a}}$ & - & (Dixon et al, 2004) \\
\hline CDI37 & ILA/4 & Malignant & + & $L^{b}, D$ & (Seaman et al, 2007) \\
\hline CDI44 & VE-cadherin & Pan-endothelial & $+^{\mathrm{a}}$ & - & (Smirnov et al, 2006) \\
\hline CDI46 & MelCAM & Pan-endothelial & $++^{\mathrm{a}}$ & $L^{b}$ & (Dignat-George et al, 2007) \\
\hline CD202b & Tie-2 & Angiogenesis & $(+)^{\mathrm{a}}$ & - & (Smirnov et al, 2006) \\
\hline CD276 & B7-H3 & Malignant & + & $D, M^{b}$ & (Seaman et al, 2007) \\
\hline CD309 & VEGFR-2 & Angiogenesis & $(+)^{\mathrm{a}}$ & $\mathrm{S}$ & (Beerepoot et al, 2004) \\
\hline WWF & & Pan-endothelial & $++^{a}$ & $P$ & (Woywodt et al, 2006) \\
\hline UEA-I & & Pan-endothelial & ++ & - & (Woywodt et al, 2006) \\
\hline DiL-AcLDL & & Pan-endothelial & ++ & - & (Voyta et al, 1984) \\
\hline
\end{tabular}

PECAM-I = platelet/endothelial cell adhesion molecule I, ICAM-I = intracellular adhesion molecule I, VCAM-I = vascular cellular adhesion molecule I, ILA/4 = inducible by lymphocyte activation /4, MeICAM= melanoma-associated cellular adhesion molecule, Tie-2=angiopoietin- I, 2, 4 receptor, B7-H3 = B7 homologue 3, VEGFR-2 = vascular endothelial growth factor receptor $2 . \mathrm{S}=$ hematopoietic stem cells, $\mathrm{L}=$ lymphocytes, $\mathrm{P}=$ platelets, $\mathrm{M}=$ monocytes, $\mathrm{E}=$ erythrocytes, $\mathrm{D}=$ dendritic cells. Expression levels: $++=$ strong, $+=$ moderate, $(+)=$ weak. ${ }^{a}$ Indicates data based on flow cytometric results from the authors. ${ }^{b}$ Indicates presence on activated cells. 
strated by global gene expression profiling, which clearly demonstrated the presence of endothelial markers (Smirnov et al, 2006). Drawbacks of this method are the costly equipment and reagents, while assay customisation is not possible. Also, the maximum number of only eight samples that can be analysed in a single run, combined with the relative long duration of a complete run (approximately $4 \mathrm{~h}$ ), limits high throughput analysis.

\section{Flow cytometry}

Flow cytometry is a widely accepted tool for immunophenotyping of cells. A cocktail of fluorochrome-labelled $\mathrm{mAb}$ is used to identify CEC, allowing a highly specific definition of CEC, and possibly, the identification of endothelial cell subsets such as EPC. Another benefit of flow cytometry is, that by multi-colour staining cells with an immunophenotypical overlap with CEC, such as endothelial micro particles and platelets, can be excluded from evaluation, which increases specificity. However, flow cytometry assays in whole blood are at risk to overestimate CEC by enumerating false-positive cells. A well-known cause of false positivity is non-specific antibody-binding. Non-specific-binding can be the result of Fc receptor-binding, binding to dead cells, or by improper use of reagents. A recent study clearly showed that the exceptionally high CEC counts found with a commonly applied flow cytometry based assay (Mancuso et al, 2001), were due to the fact that the majority of the cells designated CEC were in fact large platelets (Strijbos et al, 2007).

As a result of improper titration of the CD146 mAb cells with a $\mathrm{CD} 45^{\mathrm{dim}}, \mathrm{CD} 1^{+}$phenotype stained positively for this antigen, suggesting that CEC were enumerated. Such problems can be prevented through staining whole blood rather than a cell suspension, or through the use of a blocking reagent, by which Fc receptors are kept saturated and non-specific binding is prevented. Furthermore, addition of a real-time viability stain, such as 7 -aminoactinomycin D or propidium iodide, allows the exclusion of dead cells. Next to interference by non-specific antibody-binding, false positivity can also result from specificbinding to soluble forms of the antigen. Many endothelial surface antigens such as sCD144, and sCD146 are secreted, and their uptake by platelet aggregates can result in positivity. An effective strategy for excluding platelets, aggregates and endothelial micro particles from analysis is by using a DNA-specific stain, such as (DAPI) or 1,5-bis[2-(di-methylamino) ethyl]amino-4, 8-dihydroxyanthracene-9,10-dione (DRAQ5).

Recently, absolute CEC counts obtained by both magnetic isolation and flow cytometry assays were compared (Goon et al, 2006). The reasonable agreement in CEC counts between both methods, in combination with an established CEC phenotype (i.e. $\mathrm{CD} 34^{+}, \mathrm{CD}_{146^{+}}, \mathrm{CD}_{4} 5^{-}$), is suggestive that actual CEC counts are being approached by this flow cytometry assay. However, isolation and validation as done on the magnetically isolated cells (Rowand et al, 2007), was not performed on the CEC as defined by Goon et al (2006).

\section{CLINICAL RESULTS}

Although a large number of studies on CEC in cancer patients have been published, many of these studies rely on a flow cytometric approach, which defines $\mathrm{CEC}$ as being $\mathrm{CD} 45^{-}, \mathrm{CD} 31^{+}$, and $\mathrm{CD} 146^{+}$. Although this is a generally accepted CEC immunophenotype, reports are currently not available in which the endothelial origin of cells enumerated by those assays has been demonstrated unambiguously (Duda et al, 2006; Mancuso et al, 2006). As a result, studies on CEC that are in our opinion reliable, are scarce: only three studies are currently available, all based on CD146 driven magnetic isolation of CEC (Beerepoot et al, 2004; Woywodt et al, 2006; Rowand et al, 2007). In the first study, CEC were enumerated by magnetic isolation, followed by visual analysis of CD31, CD309 and VWF expression, determined by immunofluorescence. CEC numbers in cancer patients $\left(n=146\right.$, mean CEC $\left.399 \pm 36 \mathrm{ml}^{-1}\right)$ were found to be increased 3.3 fold when compared to healthy controls $\left(n=46\right.$, mean CEC $\left.121 \pm 16 \mathrm{ml}^{-1}\right)$. Further analysis of CEC numbers in cancer patients, demonstrated significantly higher CEC in patients with progressive disease $v s$ those with stable disease ( 95 patients, $438 \pm 65$ CEC per $\mathrm{ml}$ and 17 patients, $179 \pm 61$ CEC per ml, respectively), whereas no difference was seen between patients with stable disease and healthy donors (Beerepoot et al, 2004). The increased CEC count in cancer patients was confirmed in a study of Rowand using the CellTracks System. Cells were isolated by automated CD146 driven magnetic isolation, and assay accuracy, sensitivity, linearity and precision were assessed, Hereafter, nucleated (DAPI ${ }^{+}$) cells, expressing CD105 but lacking CD45 were enumerated in 249 healthy donors and 206 patients with metastatic cancer (Rowand et al, 2007). The observed mean CEC count of 21 in healthy controls is comparable by those found by the EUROCEC assay. Strikingly, the number of CEC reported in healthy donors was 10-fold lower when compared to those reported by Beerepoot, namely $0-20 \mathrm{ml}^{-1}$ (Rowand et al, 2007). Both groups isolate CEC using beads targeting CD146, but Beerepoot uses CD31, CD309 and VWF, rather than CD105 to confirm the endothelial origin of cells. Where CD31 and VWF are considered to be pan-endothelial cell markers, CD105 is expressed predominantly on proliferative and/or malignant CEC. Given its high recovery and reproducibility and extensive validation, we favour the CellTracks assay for isolating CEC.

\section{POTENTIAL APPLICATIONS IN ONCOLOGY}

Provided that an adequately validated, sensitive and specific assay is used, the detection and enumeration of CEC in patients with solid malignancies offer a wide spectrum of potential applications.

\section{CEC: marker for establishing prognosis and for follow-up?}

The observation that advanced cancer patients have higher CEC counts than healthy controls (Beerepoot et al, 2004; Rowand et al, 2007), whereas patients with stable disease and healthy individuals have similar numbers (Beerepoot et al, 2004), may imply that CEC enumeration may be used for prognosis and during follow-up in cancer patients. Obviously, verification of this statement would require studies in which large numbers of patients are included with enumeration of CEC at baseline and during follow-up.

\section{CEC: marker for response to treatment?}

Classic methods to establish antitumour effects of systemic agents, which rely on assessing changes in tumour size by radiological assessments, are no longer sufficient. This holds true not only when using conventional chemotherapeutic drugs, but in particular when angiogenesis inhibitors are applied. In several randomised trials exploring such drugs, enhanced progressionfree periods were observed, yet the response rates as defined by RECIST, were minimal (Yang et al, 2003). Such findings emphasize the limitations of conventional imaging, as well as the need to incorporate novel, sensitive indicators of response. The increase in CEC numbers in mice stimulated with VEGF, and the consecutive decrease of these numbers after treatment with the angiogenesis inhibitor endostatin (Schuch et al, 2003), are suggestive of a possible role for CEC in monitoring response to treatment when using agents targeting the VEGF-VEGFR pathway. Recently, a xenograft prostate cancer model showed that an increase in apoptotic CEC after treatment with thalidomide and docetaxel, was predictive for response to treatment (Li et al, 2008). However, as 
these results were based on a non-validated assay, it is important to confirm these findings using different, validated techniques.

\section{CEC: guideline for optimal drug dosing?}

Nowadays, it is increasingly recognised that the recommended dose for further exploration of a drug should be the optimal biological drug dose (OBD) rather than the MTD. The OBD is defined as the dose that is feasible to be applied in humans and yields biological effects. Changes in CEC counts after dose escalation might provide useful insights in establishing the OBD when assessing agents targeting vasculature such as VDA or angiogenesis inhibitors. A recent study by Celik et al (2005) reports a $50 \%$ decrease in CEC in tumour-bearing mice treated with endostatin. The decrease in CEC showed a clear U-shaped dose relation. The optimum dose, determined by assessment of tumour micro vessel density and analysis of tumour blood flow, resulted in the largest decrease in CEC numbers, whereas under- or over treatment resulted in a diminished decrease or even increase in CECs, suggesting a rationale for using CEC as guideline for optimum drug dosing. However, whether this holds true for humans, and for anti-angiogenic drugs other than endostatin, remains to be established.

\section{CEC: towards identification of new targets in oncology?}

One of the major advances in the management of cancer in the last decades is the introduction of targeted therapy. By identifying tumour factors that play a crucial role in the pathogenesis of a disease, an avalanche of new targets for therapy has been identified. Examination of endothelial cells from tumour vasculature, may result in the identification of antigens specific for malignant angiogenesis, such as the recently identified $\mathrm{H} 3$ homologue of the costimulatory molecule B7 (CD276) (Seaman et $a l, 2007)$, and allow the development of agents selectively targeting tumour vasculature.

\section{CEC: marker for vascular toxicity?}

With better treatment outcomes for some patient populations with advanced malignancies, there is growing interest for long-term side effects of antitumour therapies. An increased incidence of cardiovascular events has emerged as one of the most important long-term untoward sequelae. For example, patients treated with chemotherapy for advanced germ-cell cancer have a 2-7-fold increased risk for cardiovascular events when compared to the general population (Meinardi et al, 2000). Although the exact mechanism of this increased risk is unknown, in vitro data suggest that cytotoxic agents directly cause endothelial damage. Frequently used agents such as cisplatin, bleomycin and etoposide, can cause thickening of the carotid artery intima, Raynaud's phenomenon, and an increase in plasma C-reactive protein (CRP), VWF and PAI-1, all associated with endothelial dysfunction (Nuver et al, 2005). Monitoring biomarkers of endothelial dysfunction or damage such as CEC levels, both during and after treatment might provide more insight into the vascular toxicity profile of chemotherapeutic agents. On the basis of such data, less vasotoxic treatments with equivalent antitumour activity would be warranted, especially for patients for whom treatment is likely to result in long-term survival, such as in germ cell cancers, childhood lymphoblastic leukaemia and lymphoma subtypes. A recent phase I study with the protein kinase $\beta C$ inhibitor enzastaurin (Rademaker-Lakhai et al, 2007), in which CEC were enumerated by immunomagnetic isolation, did not find an effect of enzastaurin on CEC numbers. In contrast, a study on the VDA ZD6126 demonstrated a significant increase in immunomagnetically isolated CEC 2-8 h after infusion (Beerepoot et al, 2004). Given the presumed mechanism of action of VDAs, this finding strongly suggests that CEC serves as a marker to assess vascular toxicity of drugs.

\section{CONCLUSIONS}

In view of the growing recognised role of angiogenesis in oncology, and the integration of drugs targeting tumour vasculature, biomarkers that enable monitoring effects on vasculature are urgently needed. Many soluble markers, including VWF and thrombomodulin have been proposed as such markers. However, most of these are acute phase products and therefore susceptible to interference by other events frequently encountered in cancer patients such as infection. By contrast, monitoring CEC appears an attractive candidate. Several techniques have been developed to detect and enumerate CEC, but the lack of consensus on the phenotype of CEC, as well as their low numbers in blood, have resulted in conflicting results and have severely hindered progress in this important field. Providing a clear definition of CEC together with careful confirmation and validation that cell population designated 'circulating endothelial cells' are indeed CEC, are the most important issues that need to be addressed. To overcome these issues, suggestions on phenotype and detection strategy have been provided by the EUROCEC network (Woywodt et al, 2006). Despite these problems, validated assays enabling the proper enumeration of CEC are since recently available and the first results have revealed that patients with advanced cancer have indeed higher levels than healthy controls. In theory, there are many potential applications for the assessment of CEC counts in patients with solid malignancies including establishing prognosis and therapy-induced effects, but whether or not CEC can actually be used for these purposes is currently the subject of clinical studies. So only time will tell whether CEC can fulfil its promise as a biomarker in clinical oncology.

\section{REFERENCES}

Beerepoot LV, Radema SA, Witteveen EO, Thomas T, Wheeler C, Kempin S, Voest EE (2006) Phase I clinical evaluation of weekly administration of the novel vascular-targetting agent, ZD6126, in patients with solid tumors. J Clin Oncol 24: $1491-1488$

Celik I, Surucu O, Dietz C, Heymach JV, Force J, Hoschele I, Becker CM, Folkman J, Kisker O (2005) Therapeutic efficacy of endostatin exhibits a biphasic dose-response curve. Cancer research 65: $11044-11050$

Corcoran TB, O'Shea A, Engel A, Shorten GD (2006) The influence of propofol on $\mathrm{P}$-selectin expression and nitric oxide production in re-oxygenated human umbilical vein endothelial cells. Acta anaesthesiologica Scandinavica 50: $348-354$
Dignat-George F, Sabatier F, Blann A, Woywodt A (2007) Detection of circulating endothelial cells: CD146-based magnetic separation enrichment or flow cytometric assay? J Clin Oncol 25: e1 - e2; author reply e3 - 5

Dixon GL, Heyderman RS, van der Ley P, Klein NJ (2004) High-level endothelial E-selectin (CD62E) cell adhesion molecule expression by a lipopolysaccharide-deficient strain of Neisseria meningitidis despite poor activation of NF-kappaB transcription factor. Clin Exp Immunol 135: 85-93

Duda DG, Cohen KS, di Tomaso E, Au P, Klein RJ, Scadden DT, Willett CG, Jain RK (2006) Differential CD146 expression on circulating vs tissue endothelial cells in rectal cancer patients: implications for circulating endothelial and progenitor cells as biomarkers for antiangiogenic therapy. J Clin Oncol 24: 1449-1453 
Elshal MF, Khan SS, Takahashi Y, Solomon MA, McCoy Jr JP (2005) CD146 (Mel-CAM), an adhesion marker of endothelial cells, is a novel marker of lymphocyte subset activation in normal peripheral blood. Blood 106: $2923-2924$

Furstenberger G, von Moos R, Lucas R, Thurlimann B, Senn HJ, Hamacher J, Boneberg EM (2006) Circulating endothelial cells and angiogenic serum factors during neoadjuvant chemotherapy of primary breast cancer. $B r$ cancer 94: 524-531

George F, Brisson C, Poncelet P, Laurent JC, Massot O, Arnoux D, Ambrosi P, Klein-Soyer C, Cazenave JP, Sampol J (1992) Rapid isolation of human endothelial cells from whole blood using S-Endol monoclonal antibody coupled to immuno-magnetic beads: demonstration of endothelial injury after angioplasty. Thrombosis and haemostasis 67: 147-153

Goon PK, Boos CJ, Stonelake PS, Blann AD, Lip GY (2006) Detection and quantification of mature circulating endothelial cells using flow cytometry and immunomagnetic beads: a methodological comparison. Thrombosis and haemostasis 96: 45-52

Kabbinavar F, Hurwitz HI, Fehrenbacher L, Meropol NJ, Novotny WF, Lieberman G, Griffing S, Bergsland E (2003) Phase II, randomized trial comparing bevacizumab plus fluorouracil (FU)/leucovorin (LV) with FU/LV alone in patients with metastatic colorectal cancer. J Clin Oncol 21: 60-65

Li H, Raia V, Bertolini F, Price DK, Figg WD (2008) Circulating endothelial cells as a therapeutic marker for thalidomide in combined therapy with chemotherapy drugs in a human prostate cancer model. BJU Int 101(7): $884-888$

Lyden D, Hattori K, Dias S, Costa C, Blaikie P, Butros L, Chadburn A, Heissig B, Marks W, Witte L, Wu Y, Hicklin D, Zhu Z, Hackett NR, Crystal RG, Moore MA, Hajjar KA, Manova K, Benezra R, Rafii S (2001) Impaired recruitment of bone-marrow-derived endothelial and hematopoietic precursor cells blocks tumor angiogenesis and growth. Nat Med 7: $1194-1201$

Mancuso P, Burlini A, Pruneri G, Goldhirsch A, Martinelli G, Bertolini F (2001) Resting and activated endothelial cells are increased in the peripheral blood of cancer patients. Blood 97: 3658-3661

Mancuso P, Colleoni M, Calleri A, Orlando L, Maisonneuve P, Pruneri G, Agliano A, Goldhirsch A, Shaked Y, Kerbel RS, Bertolini F (2006) Circulating endothelial-cell kinetics and viability predict survival in breast cancer patients receiving metronomic chemotherapy. Blood 108: $452-459$

Meinardi MT, Gietema JA, van der Graaf WT, van Veldhuisen DJ, Runne MA, Sluiter WJ, de Vries EG, Willemse PB, Mulder NH, van den Berg MP, Koops HS, Sleijfer DT (2000) Cardiovascular morbidity in long-term survivors of metastatic testicular cancer. J Clin Oncol 18: $1725-1732$

Moroni G, Del Papa N, Moronetti LM, Vitali C, Maglione W, Comina DP, Urgnani F, Sandri S, Ponticelli C, Cortelezzi A (2005) Increased levels of circulating endothelial cells in chronic periaortitis as a marker of active disease. Kidney international 68: $562-568$

Motzer RJ, Hutson TE, Tomczak P, Michaelson MD, Bukowski RM, Rixe O, Oudard S, Negrier S, Szczylik C, Kim ST, Chen I, Bycott PW, Baum CM, Figlin RA (2007) Sunitinib vs interferon alfa in metastatic renal-cell carcinoma. The New England journal of medicine 356: 115-124
Naumov GN, Bender E, Zurakowski D, Kang SY, Sampson D, Flynn E, Watnick RS, Straume O, Akslen LA, Folkman J, Almog N (2006) A model of human tumor dormancy: an angiogenic switch from the nonangiogenic phenotype. Journal of the National Cancer Institute 98: 316-325

Nuver J, Smit AJ, van der Meer J, van den Berg MP, van der Graaf WT, Meinardi MT, Sleijfer DT, Hoekstra HJ, van Gessel AI, van Roon AM, Gietema JA (2005) Acute chemotherapy-induced cardiovascular changes in patients with testicular cancer. J Clin Oncol 23: 9130-9137

Peters BA, Diaz LA, Polyak K, Meszler L, Romans K, Guinan EC, Antin JH, Myerson D, Hamilton SR, Vogelstein B, Kinzler KW, Lengauer C (2005) Contribution of bone marrow-derived endothelial cells to human tumor vasculature. Nat Med 11: 261-262

Rademaker-Lakhai JM, Beerepoot LV, Mehra N, Radema SA, van Maanen R, Vermaat JS, Witteveen EO, Visseren-Grul CM, Musib L, Enas N, van Hal G, Beijnen JH, Schellens JH, Voest EE (2007) Phase I pharmacokinetic and pharmacodynamic study of the oral protein kinase $C$ betainhibitor enzastaurin in combination with gemcitabine and cisplatin in patients with advanced cancer. Clin Cancer Res 13: 4474-4481

Rowand JL, Martin G, Doyle GV, Miller MC, Pierce MS, Connelly MC, Rao C, Terstappen LW (2007) Endothelial cells in peripheral blood of healthy subjects and patients with metastatic carcinomas. Cytometry $A$ 71: $105-113$

Sandler A, Gray R, Perry MC, Brahmer J, Schiller JH, Dowlati A, Lilenbaum R, Johnson DH (2006) Paclitaxel-carboplatin alone or with bevacizumab for non-small-cell lung cancer. The New England journal of medicine 355: $2542-2550$

Schuch G, Heymach JV, Nomi M, Machluf M, Force J, Atala A, Eder Jr JP, Folkman J, Soker S (2003) Endostatin inhibits the vascular endothelial growth factor-induced mobilization of endothelial progenitor cells. Cancer research 63: 8345-8350

Seaman S, Stevens J, Yang MY, Logsdon D, Graff-Cherry C, St Croix B (2007) Genes that distinguish physiological and pathological angiogenesis. Cancer Cell 11: 539-554

Smirnov DA, Foulk BW, Doyle GV, Connelly MC, Terstappen LW, O'Hara SM (2006) Global gene expression profiling of circulating endothelial cells in patients with metastatic carcinomas. Cancer research 66: $2918-2922$

Strijbos MH, Kraan J, den Bakker MA, Lambrecht BN, Sleijfer S, Gratama JW (2007) Cells meeting our immunophenotypic criteria of endothelial cells are large platelets. Cytometry 72: 86-93

Voyta JC, Via DP, Butterfield CE, Zetter BR (1984) Identification and isolation of endothelial cells based on their increased uptake of acetylated-low density lipoprotein. The Journal of cell biology 99: 2034-2040

Woywodt A, Blann AD, Kirsch T, Erdbruegger U, Banzet N, Haubitz M, Dignat-George F (2006) Isolation and enumeration of circulating endothelial cells by immunomagnetic isolation: proposal of a definition and a consensus protocol. J Thromb Haemost 4: 671-677

Yang JC, Haworth L, Sherry RM, Hwu P, Schwartzentruber DJ, Topalian SL, Steinberg SM, Chen HX, Rosenberg SA (2003) A randomized trial of bevacizumab, an anti-vascular endothelial growth factor antibody, for metastatic renal cancer. The New England journal of medicine 349: 427 - 434 